\title{
Selection of Saccharomyces cerevisiae strains for efficient very high gravity bio-ethanol fermentation processes
}

\author{
Francisco B. Pereira • Pedro M. R. Guimarães • \\ José A. Teixeira $\cdot$ Lucília Domingues
}

Received: 26 April 2010/Accepted: 14 June 2010/Published online: 24 June 2010

(C) Springer Science+Business Media B.V. 2010

\begin{abstract}
An optimized very high gravity (VHG) glucose medium supplemented with low cost nutrient sources was used to evaluate bio-ethanol production by 11 Saccharomyces cerevisiae strains. The industrial strains PE-2 and CA1185 exhibited the best overall fermentation performance, producing an ethanol titre of $19.2 \%(\mathrm{v} / \mathrm{v})$ corresponding to a batch productivity of $2.5 \mathrm{~g} \mathrm{l}^{-1} \mathrm{~h}^{-1}$, while the best laboratory strain (CEN.PK 113-7D) produced $17.5 \%(\mathrm{v} / \mathrm{v})$ ethanol with a productivity of $1.7 \mathrm{~g} \mathrm{l}^{-1} \mathrm{~h}^{-1}$. The results presented here emphasize the biodiversity found within $S$. cerevisiae species and that naturally adapted strains, such as PE-2 and CA1185, are likely to play a key role in facilitating the transition from laboratory technological breakthroughs to industrialscale bio-ethanol fermentations.
\end{abstract}

Keywords Bio-ethanol production . Industrial strains - Laboratory strains .

Saccharomyces cerevisiae .

Very high gravity fermentation

F. B. Pereira · P. M. R. Guimarães · J. A. Teixeira ·

L. Domingues $(\varangle)$

IBB - Institute for Biotechnology and Bioengineering, Centre of Biological Engineering, Universidade do Minho, Campus de Gualtar, 4710-057 Braga, Portugal

e-mail: luciliad@deb.uminho.pt

\section{Introduction}

The application of very high gravity (VHG) fermentation technology, i.e. the use of highly concentrated sugar substrates, for the industrial production of bioethanol has a number of benefits, including: decreased process water requirements and energy costs, increased overall plant productivity and higher ethanol concentrations in the fermentation product that allow considerable savings in energy for distillation (Wang et al. 2007). Although many microorganisms have been exploited for ethanol production, Saccharomyces cerevisiae strains are the most widely used in large-scale industrial bio-ethanol fermentation, namely due to their ability to ferment a wide range of sugars and develop appropriate mechanisms to deal with the harmful stress conditions found in VHG processes (Bai et al. 2008). Nevertheless, within $S$. cerevisiae species a wide variety of characteristics is observed, in particular between the so-called industrial and laboratory strains.

The fermentation processes under harsh industrial environmental conditions, especially using VHG media, require industrial strains (Silva-Filho et al. 2005). These strains rapidly respond to the stress conditions by adjusting their metabolic activities and become adapted over a long time in their specific environment (Zhao and Bai 2009). Genetically, these are usually polyploid, aneuploid, or even alloploid and genetic manipulations, although feasible, are rather complex and seldom reported in literature 
(Hansen and Kielland-Brandt 1996). In contrast, the laboratory strains are often haploid or diploid, well documented, and easily manipulated by using modern molecular biology and metabolic engineering tools (Albers and Larsson 2009). Although attractive in this respect, the performance of laboratory strains is generally weak under the very harsh conditions found in VHG industrial fermentations.

Spontaneous fermentation of high sugar juice is the main step in traditional "cachaça" (typical Brazilian distilled beverage) production and that is usually carried out by a mixed culture of yeasts, with predominance of $S$. cerevisiae strains physiologically adapted to the harsh environmental conditions (Schwan et al. 2001). Some strains of S. cerevisiae isolated from Brazilian sugarcane-to-ethanol distilleries showed high tolerance to ethanol and combined high fermentation efficiency with prolonged persistence in the fermentation system. In recent years, such strains have been widely adopted by the industry (Basso et al. 2008) and one of the most successful examples is the PE-2 wild isolate currently used by $\sim 30 \%$ of Brazilian distilleries, generating $\sim 10 \%$ of the world's bio-ethanol supply (Argueso et al. 2009).

The aim of this work was to evaluate and compare the performance of laboratory and industrial strains under VHG batch fermentation conditions, in order to select the strain(s) that allow obtaining the highest ethanol titre and productivity.

\section{Materials and methods}

\section{Yeasts}

The $S$. cerevisiae strains used included eight industrial strains: three isolated from Brazilian bio-ethanol production plants-PE-2, CAT-1, VR-1 (Basso et al. 2008) - and five belonging to the UFLA collection (Federal University of Lavras, Brazil) isolated from "cachaça" fermentation processes-CA11, CA1162, CA1185, CA1187, CA155 (Table 1). The S. cerevisiae laboratory strains (routinely used in yeast research laboratories) included haploid S288C, haploid CEN.PK 113-7D and diploid CEN.PK 122 (Table 1). Stock cultures were maintained on YPD [1\% (w/v) yeast extract, $2 \%(\mathrm{w} / \mathrm{v})$ bacto-peptone and $2 \%(\mathrm{w} / \mathrm{v})$ glucose] agar plates at $4^{\circ} \mathrm{C}$.
Media and fermentations

The fermentation tests were performed in a previously optimized VHG medium (Pereira et al. 2010) consisting of $280-350 \mathrm{~g}$ glucose $1^{-1}, 44.3 \mathrm{~g}$ corn steep liquor $(\mathrm{CSL}) \mathrm{l}^{-1}, 2.3 \mathrm{~g}$ urea $\mathrm{l}^{-1}, 3.8 \mathrm{~g} \mathrm{MgSO}_{4}$. $7 \mathrm{H}_{2} \mathrm{O}^{-1}$ and $0.03 \mathrm{~g} \mathrm{CuSO} \cdot 5 \mathrm{H}_{2} \mathrm{O}^{-1}$. Glucose syrup and CSL were kindly provided by a starch manufacturer (COPAM, Portugal) and autoclaved separately $\left(121^{\circ} \mathrm{C}, 20 \mathrm{~min}\right)$. After autoclaving, the whole CSL was allowed to settle for $1-2$ days at $4^{\circ} \mathrm{C}$ and then centrifuged $(15 \mathrm{~min}$ at $13100 \times \mathrm{g})$ to remove the insolubles. The main composition of the CSL used has been previously reported (Pereira et al. 2010). The nutrients concentrated stock solutions were sterilized by filtration and then added aseptically. Before inoculating the fermentation flasks the medium was aerated by stirring with a magnet $(>850 \mathrm{rpm}$ during $20 \mathrm{~min}$ ), reaching $>95 \%$ of air saturation.

The yeast for inoculation was grown in Erlenmeyer flasks filled with medium containing $50 \mathrm{~g}$ glucose $1^{-1}$, $20 \mathrm{~g}$ peptone $1^{-1}$ and $10 \mathrm{~g}$ yeast extract $1^{-1}$. After incubation at $30^{\circ} \mathrm{C}$ and $150 \mathrm{rpm}$ for $18-22 \mathrm{~h}\left(\mathrm{OD}_{600}\right.$ of 7-7.5), the cell suspension was aseptically collected by centrifugation $\left(10 \mathrm{~min}\right.$ at $\left.7500 \times g, 4^{\circ} \mathrm{C}\right)$ and ressuspended in $0.9 \%(\mathrm{w} / \mathrm{v}) \mathrm{NaCl}$ to a concentration of $200 \mathrm{mg}$ fresh yeast $\mathrm{ml}^{-1}$. Then, the yeast cells were pitched at about $1.3 \times 10^{8}$ cells ml ${ }^{-1}$ into $40 \mathrm{ml}$ of culture medium to start the fermentation.

Fermentations were done in $100 \mathrm{ml}$ Erlenmeyer flasks fitted with perforated rubber stoppers enclosing glycerol-locks (to permit $\mathrm{CO}_{2}$ exhaustion while avoiding the entrance of air) and incubated at $30^{\circ} \mathrm{C}$ with $150 \mathrm{rpm}$ orbital agitation. The initial $\mathrm{pH}$ was adjusted to 5.5 with $\mathrm{NaOH}$. The final $\mathrm{pH}$ was $>3.9$ in all fermentations. The fermentation evolution was monitored by mass loss and samples for analyses were taken just at the ending point.

\section{Analytical procedures}

Cell dry weight was determined using $20 \mathrm{ml}$ samples of the yeast culture collected by centrifugation $\left(10 \mathrm{~min}\right.$ at $\left.7500 \times g, 4^{\circ} \mathrm{C}\right)$ in a pre-weighed dried tube and then washed with $20 \mathrm{ml}$ of distilled water. The tube was dried overnight at $105^{\circ} \mathrm{C}$ and weighed again. Glucose, ethanol and glycerol were analyzed by HPLC, using a Varian MetaCarb $87 \mathrm{H}$ column 
Table 1 S. cerevisiae strains used in this study

a European Saccharomyces cerevisiae Archive for Functional Analysis (euroscarf@em.unifrankfurt.de)

b American Type Culture Collection (www.atcc.org)

c LNF Latino Americana, Brazil (lnf@lnf.com.br)

d Federal University of Lavras, Brazil (rschwan@dbi.ufla.br)

\begin{tabular}{lll}
\hline Strain & $\begin{array}{l}\text { Available } \\
\text { from }\end{array}$ & Reference/source \\
\hline CEN.PK 113-7D & EUROSCARF $^{\text {a collection }}$ & van Dijken et al. (2000) \\
CEN.PK 122 & EUROSCARF $^{\text {a collection }}$ & van Dijken et al. (2000) \\
S288C & ATCC $^{\mathrm{b}}$ collection (no 26108) & Mortimer and Johnston (1986) \\
PE-2 & $\mathrm{LNF}^{\mathrm{c}}$ & Basso et al. (2008) \\
VR-1 & $\mathrm{LNF}^{\mathrm{c}}$ & Basso et al. (2008) \\
CAT-1 & $\mathrm{LNF}^{\mathrm{c}}$ & Basso et al. (2008) \\
CA11 & $\mathrm{LNF}^{\mathrm{c}}$ & R. Schwan \\
CA1162 & $\mathrm{UFLA}^{\mathrm{d}}$ collection & R. Schwan \\
CA1185 & $\mathrm{UFLA}^{\mathrm{d}}$ collection & R. Schwan \\
CA1187 & $\mathrm{UFLA}^{\mathrm{d}}$ collection & R. Schwan \\
CA155 & $\mathrm{UFLA}^{\mathrm{d}}$ collection & R. Schwan \\
\hline
\end{tabular}

eluted at $60^{\circ} \mathrm{C}$ with $0.005 \mathrm{M} \mathrm{H}_{2} \mathrm{SO}_{4}$ at a flow rate of $0.7 \mathrm{ml} \mathrm{min}{ }^{-1}$, and a refractive-index detector.

\section{Determination of fermentation parameters}

Ethanol conversion yield was calculated by the ratio between the maximum ethanol concentration produced and the glucose consumed (difference between the initial and residual glucose concentrations). It was expressed as a percentage (\%) of the theoretical conversion yield, i.e. the yield considering a production of $0.511 \mathrm{~g}$ of ethanol per $\mathrm{g}$ of glucose. Ethanol productivity was defined as the ratio between final ethanol concentration and total fermentation time (fermentation was considered to be complete when the weight of the flasks stabilized).

\section{Results and discussion}

An optimized VHG medium (280-350 g glucose $1^{-1}$ ) supplemented with low-cost nutrients was used to evaluate the fermentation performance of three standard laboratory strains and eight industrial strains, three isolated from bio-ethanol distilleries and five from "cachaça" fermentations in Brazil.

Figure 1 shows the $\mathrm{CO}_{2}$ production (mass loss) profiles for the 11 strains tested. These profiles permit the evaluation of fermentation evolution since under the oxygen-limiting conditions used in this study, the patterns of $\mathrm{CO}_{2}$ and ethanol production are closely related, because most $\mathrm{CO}_{2}$ originates from the fermentative pathway. The fermentation parameters determined at the end of the fermentations are shown in Fig. 2.

Among the laboratory strains, CEN.PK 113-7D presented the best fermentation performance, producing $17.5 \%(\mathrm{v} / \mathrm{v})$ ethanol in less than $80 \mathrm{~h}$. The behaviour of the diploid version CEN.PK 122 was similar, with fermentation being slightly slower (Fig. 1a). Fermentation by strain S288C was much slower, taking over $120 \mathrm{~h}$ to reach completion, but the final ethanol titre reached was only slightly lower (Fig. 2a). The three strains were able to completely consume initial glucose concentrations close to $300 \mathrm{~g} \mathrm{l}^{-1}$ (Fig. 2c), with ethanol yields over $90 \%$ of the theoretical (Fig. 2b). However, when the initial glucose concentration was raised to about $330 \mathrm{~g} \mathrm{l}^{-1}$, fermentation by strain CEN.PK 113-7D was slower and stopped with $36 \mathrm{~g}$ of residual glucose $\mathrm{l}^{-1}$ (data not shown). Hence, this increase in the initial glucose concentration resulted in a decrease in the fermentation rate and, consequently, in the overall ethanol productivity (which dropped to $1.5 \mathrm{~g}^{-1} \mathrm{~h}^{-1}$ ), probably due to the increased osmotic pressure (higher content of sugar) in the beginning of the fermentation.

The industrial strains were tested with higher glucose concentrations (ca. $330 \mathrm{~g} \mathrm{l}^{-1}$ ) (Fig. 2c). Among the strains isolated from bio-ethanol distilleries, strains PE-2 and VR-1 showed identical $\mathrm{CO}_{2}$ production profiles, with fermentation reaching completion in less than $80 \mathrm{~h}$, while strain CAT-1 was slower (Fig. 1b). The three strains consumed nearly all glucose (residual $<1 \mathrm{~g}^{-1}$ ) (Fig. 2c) but PE-2 produced a higher final ethanol titre $(19 \% \mathrm{v} / \mathrm{v})$ 

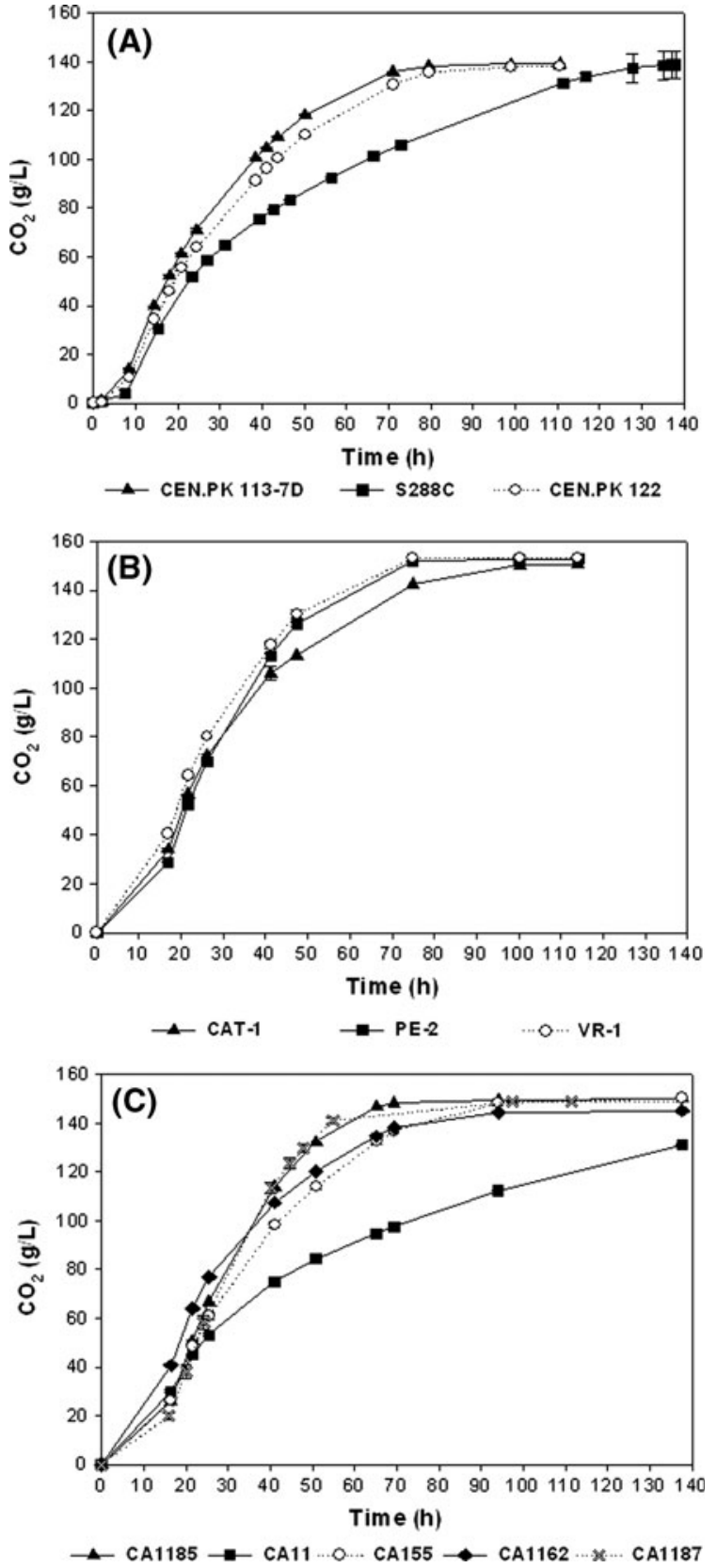

Fig. 1 Profiles of $\mathrm{CO}_{2}$ production obtained in VHG fermentations: a ca. $300 \mathrm{~g}$ glucose $\mathrm{1}^{-1}$ by laboratory strains, b ca. $330 \mathrm{~g}$ glucose $1^{-1}$ by industrial strains isolated from bioethanol distilleries, $\mathbf{c}$ ca. $330 \mathrm{~g}$ glucose $1^{-1}$ by industrial yeast strains isolated from "cachaça" fermentation

(Fig. 2a) and consequently presented a better ethanol yield (90\% of theoretical) (Fig. 2b).

Among the strains isolated from "cachaça" environments, CA1185 and CA1187 showed similar
$\mathrm{CO}_{2}$ production profiles, with fermentation reaching completion in less than $80 \mathrm{~h}$ (Fig. 1c), in agreement with the results obtained for strain PE-2 and VR-1 (Fig. 1b). Fermentation by strain CA155 was slower but reached identical final $\mathrm{CO}_{2}$ production, with total glucose consumption. These three strains produced over $18 \%$ (v/v) ethanol (Fig. 2a), with conversion yields over $85 \%$ of theoretical (Fig. 2b). Fermentation by strain CA1162 was slower (Fig. 1c), producing $17 \%(\mathrm{v} / \mathrm{v})$ ethanol but leaving a glucose residual of $13 \mathrm{~g} \mathrm{l}^{-1}$ (Fig. 2). Strain CA11 showed the slowest fermentation amongst the industrial strains, with fermentation being incomplete even after $140 \mathrm{~h}$ (Figs. 1c, 2c).

These results indicate that there is heterogeneity among these natural yeast isolates in their ability to ferment VHG glucose medium and in their response to stress conditions. Accordingly, using different molecular techniques Pataro et al. (2000) observed high molecular diversity of the prevalent $S$. cerevisiae strains in "cachaça" production, which was attributed to a succession of indigenous strains that occur throughout the "cachaça" fermentation season and among different seasons.

In order to investigate the maximum ethanol titres that could be produced, strains PE-2, CA1185 and CA1187 were tested in fermentations with $350 \mathrm{~g}$ glucose $1^{-1}$ (data not shown). These strains fermented nearly all the glucose (residual $<4 \mathrm{~g} \mathrm{l}^{-1}$ ), reaching ethanol titres of $19.2 \pm 0.3,19.2 \pm 0.0$ and $18.1 \pm 0.0 \%(\mathrm{v} / \mathrm{v})$, respectively. Strains PE-2 and CA1185 showed the higher ethanol productivity $\left(2.5 \mathrm{~g} \mathrm{l}^{-1} \mathrm{~h}^{-1}\right)$, which was lower in the case of CA1187 $\left(1.8 \mathrm{~g}^{-1} \mathrm{~h}^{-1}\right)$.

Laboratory strains showed a final biomass concentration around 7-8 $\mathrm{g} \mathrm{l}^{-1}$, which was lower than that obtained with industrial strains (8-11 $\mathrm{g} \mathrm{l}^{-1}$ ) (Fig. 2d). This higher growth of industrial strains on VHG conditions can be related to its origin, since these strains were isolated from stressful environments and were physiologically adapted to media with high osmotic pressure and ethanol stress (Basso et al. 2008).

There were no considerable differences in glycerol biosynthesis by the laboratory strains with a concentration around $8 \mathrm{~g}^{-1}$ being obtained at the end of the fermentations, corresponding to $5-6 \%$ of the final ethanol concentration (Fig. 2d). Interestingly, the industrial strains produced proportionately more glycerol, which accumulated to $8-10 \%$ of the final 

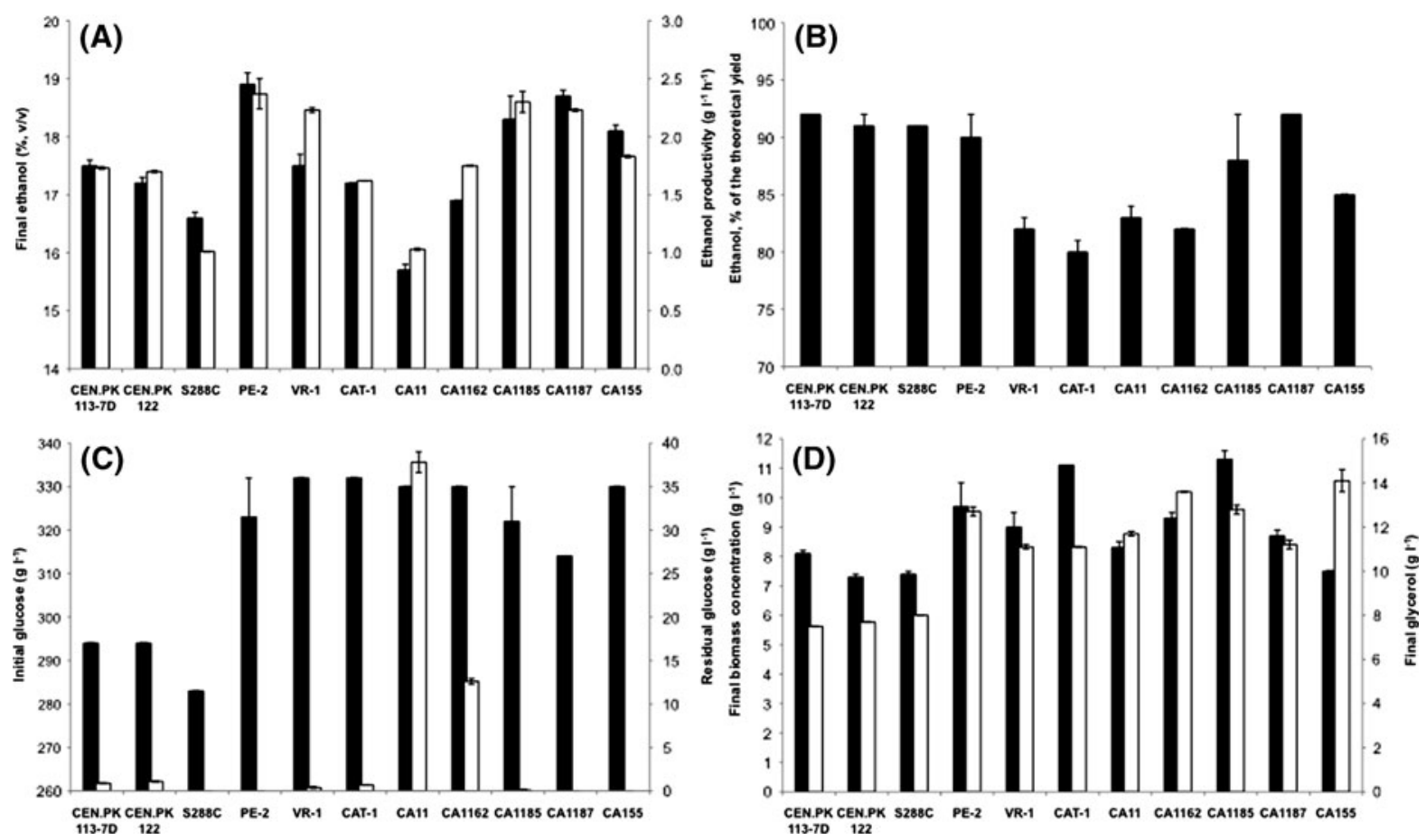

Fig. 2 VHG fermentations with laboratory and industrial $S$. cerevisiae strains: a final ethanol concentration (dark columns) and ethanol productivity (white columns), b ethanol yield, c initial glucose concentration (dark columns) and final glucose concentration (white columns), d final biomass

ethanol concentration (Fig. 2d). This increase in glycerol levels may contribute to counteract the effect of increasing osmotic pressure, promoting a protective effect on yeast cells (Kaino and Takagi 2008).

Increasing ethanol concentration at the end of fermentation (by applying high content of substrate) can significantly save the energy consumption in the downstream processes (Zhao and Bai 2009). Nevertheless, the osmotic pressure and ethanol inhibition developed under VHG conditions frequently result in incomplete or stuck fermentations with consequent losses in productivity and raw material. However, our results showed that robust strains isolated from stressful industrial environments, such as PE-2 and CA1185, were able to consume over $330 \mathrm{~g}$ glucose $1^{-1}$ and produce high ethanol titres (up to 19\%) with high ethanol batch productivity $\left(>2.3 \mathrm{~g} \mathrm{l}^{-1} \mathrm{~h}^{-1}\right)$. The results suggest that these strains are more prepared to cope with VHG fermentation stresses, namely high ethanol concentrations and osmotic pressure, comparing to standard laboratory yeast strains.

concentration (dark columns) and final glycerol concentration (white columns). Error bars represent the range between independent biological duplicates, except for the PE-2 and CA1185 data for which the error bars represent the standard deviation of four independent biological replicates

These industrial yeasts must sense and rapidly adapt to the adverse factors found in their natural environment, adjusting their physiology and metabolic activities to avoid substantial viability loss in the culture. Silva-Filho et al. (2005) concluded by PCRfingerprinting of yeast samples from fuel ethanol fermentations that indigenous strains could be more adapted to the industrial process than commercial ones. Probably, during yeast cell recycling, selective pressure (an adaptive evolution) is imposed on yeast population, leading to strains with higher tolerance to the stressful conditions of the industrial fermentation. The results of the present study show that the great biodiversity found in distillery environments can be an important source of robust stress-tolerant strains for biotechnological fermentation processes. These robust strains also constitute interesting hosts to be used in improvement programs through metabolic engineering.

Ethanol concentrations above $18 \% \quad(\mathrm{v} / \mathrm{v})$, as obtained with strains PE-2, CA1185, CA1187 and 
CA155 (Fig. 2a), are rarely reported in the literature. Additionally, the ethanol productivities attained $\left(>2.3 \mathrm{~g} \mathrm{l}^{-1} \mathrm{~h}^{-1}\right)$ are very interesting for batch VHG fermentation. To our knowledge, the highest ethanol titres $(20.6-23.8 \% \mathrm{v} / \mathrm{v})$ have been reported in fermentations of VHG wheat mashes at temperatures not higher than $27^{\circ} \mathrm{C}$ (see Jones and Ingledew 1994 and references therein). In Brazil 70-80\% of the distilleries producing bio-ethanol from sugarcane employ a fed-batch process with high yeast cell concentrations and high fermentation temperature (above $30^{\circ} \mathrm{C}$ ) achieving fermentation times of only $6-10 \mathrm{~h}$ and final ethanol concentrations up to $11 \%(\mathrm{v} / \mathrm{v})$ (Brethauer and Wyman 2009). Intensification of the fermentation process could lead to higher ethanol titres, which would be beneficial for process economics due to energy savings in the distillation process. In fact, in the United States, some corn-to-ethanol distilleries are already obtaining fermentation products with 16-18\% (v/v) ethanol (Shapouri and Gallagher 2005).

\section{Conclusions}

The application of VHG fermentation for fuel ethanol production can improve the final ethanol concentration and save significantly energy consumption. Our results highlight industrial distillery environments as a remarkable source of robust yeast strains for biotechnological fermentation processes. The industrial strains PE-2 and CA1185 exhibited the best overall fermentation performance, efficiently fermenting $330-350 \mathrm{~g}$ glucose $1^{-1}$ producing over $19 \%(\mathrm{v} / \mathrm{v})$ ethanol with a batch productivity up to $2.5 \mathrm{~g}^{-1} \mathrm{~h}^{-1}$. Among the laboratory strains, the haploid CEN.PK 113-7D presented the best VHG fermentation efficiency, consuming $300 \mathrm{~g}$ glucose $1^{-1}$ with a production of $17.5 \%(\mathrm{v} / \mathrm{v})$ ethanol, corresponding to a productivity of $1.7 \mathrm{~g} \mathrm{l}^{-1} \mathrm{~h}^{-1}$. These results are of practical importance for the selection of suitable yeast strains for the development of highly efficient industrial VHG bio-ethanol fermentation systems.

Acknowledgements The authors thank COPAM — Companhia Portuguesa de Amidos, S.A. (Portugal) for kindly providing glucose syrup and CSL, and Whasley Duarte and Rosane Schwan (Federal University of Lavras, Brazil) for kindly providing the yeast strains (isolated from Brazilian "cachaça" and bio-ethanol fermentations). The financial support of Fundação para a Ciência e a Tecnologia (FCT), Portugal, is acknowledged: project ProBioethanol PTDC/BIO/66151/2006, Grant SFRH/ BD/64776/2009 to F. B. Pereira and Grant SFRH/BPD/44328/ 2008 to P. M. R. Guimarães.

\section{References}

Albers E, Larsson C (2009) A comparison of stress tolerance in YPD and industrial lignocellulose-based medium among industrial and laboratory yeast strains. J Ind Microbiol Biotechnol 36:1085-1091

Argueso JL, Carazzolle MF, Mieczkowski PA, Duarte FM, Netto OVC, Missawa SK, Galzerani F, Costa GGL, Vidal RO, Noronha MF et al (2009) Genome structure of a Saccharomyces cerevisiae strain widely used in bioethanol production. Genome Res 19:2258-2270

Bai FW, Anderson WA, Moo-Young M (2008) Ethanol fermentation technologies from sugar and starch feedstocks. Biotechnol Adv 26:89-105

Basso LC, de Amorim HV, de Oliveira AJ, Lopes ML (2008) Yeast selection for fuel ethanol production in Brazil. FEMS Yeast Res 8:1155-1163

Brethauer S, Wyman EC (2009) Review: continuous hydrolysis and fermentation for cellulosic ethanol production. Bioresour Technol 101:4862-4874

Hansen J, Kielland-Brandt MC (1996) Modification of biochemical pathways in industrial yeasts. J Biotechnol 49: $1-12$

Jones AM, Ingledew WM (1994) Fuel alcohol production: optimization of temperature for efficient very-high-gravity fermentation. Appl Environ Microbiol 60:1048-1051

Kaino T, Takagi H (2008) Gene expression profiles and intracellular contents of stress protectants in Saccharomyces cerevisiae under ethanol and sorbitol stresses. Appl Microbiol Biotechnol 79:273-283

Mortimer RK, Johnston JR (1986) Genealogy of principal strains of the yeast genetic stock center. Genetics 113: $35-43$

Pataro C, Guerra JB, Petrillo-Peixoto ML, Mendonca-Hagler LC, Linardi VR, Rosa CA (2000) Yeast communities and genetic polymorphism of Saccharomyces cerevisiae strains associated with artisanal fermentation in Brazil. J Appl Microbiol 89:24-31

Pereira FB, Guimarães PMR, Teixeira JA, Domingues L (2010) Optimization of low-cost medium for very high gravity ethanol fermentations by Saccharomyces cerevisiae using statistical experimental designs. Bioresour Technol. doi:10.1016/j.biortech.2010.04.082

Schwan RF, Mendonca AT, da Silva JJ, Rodrigues V, Wheals AE (2001) Microbiology and physiology of Cachaca (Aguardente) fermentations. Antonie Van Leeuwenhoek 79:89-96

Shapouri H, Gallagher P (2005) USDA's 2002 ethanol costof-production survey. Agriculture Economic Report Number 841, United States Department of Agriculture

Silva-Filho EA, Brito dos Santos SK, Resende Ado M, Morais JO, Morais MA Jr, Ardaillon Simões D (2005) Yeast population dynamics of industrial fuel-ethanol fermentation process assessed by PCR-fingerprinting. Antonie Van Leeuwenhoek 88:13-23 
van Dijken JP, Bauer J, Brambilla L, Duboc P, François JM, Gancedo C, Giuseppin MLF, Heijnen JJ, Hoare M, Lange HC, Madden EA, Niederberger P, Nielsen J, Parrou JL, Petit T, Porro D, Reuss M, van Riel N, Rizzi M, Steensma HY, Verrips CT, Vindelov J, Pronk JT (2000) An interlaboratory comparison of physiological and genetic properties of four Saccharomyces cerevisiae strains. Enzyme Microb Technol 26:706-714
Wang FQ, Gao CJ, Yang CY, Xu P (2007) Optimization of an ethanol production medium in very high gravity fermentation. Biotechnol Lett 29:233-236

Zhao XQ, Bai FW (2009) Yeast flocculation: new story in fuel ethanol production. Biotechnol Adv 27:849-856 